\title{
Efeito da irradiação em carne de coelho congelada
}

\author{
Effect of the irradiation in meat of frozen rabbit
}

\author{
Adriana Régia Marques de SOUZA ${ }^{1}$, Valter ARTHUR ${ }^{1}$, \\ Solange Guidolin CANNIATTI-BRAZACA ${ }^{2 *}$, Meylene Aparecida Luzia COUTO²
}

\section{Resumo}

O crescimento nacional da produção de carne de coelhos necessita de maior conhecimento sobre características da carne, bem como o efeito de um processo que permita sua maior conservação. Os cortes congelados da carne de coelho: coxa, pernil e lombo, tratados com dois tipos de antibióticos, norfloxacina e ciprofloxacina, foram irradiados nas doses de 0, 3 e $6 \mathrm{kGy}$ e determinados os teores de ferro heme e não heme dos cortes. As doses de irradiação empregadas foram influentes nos teores de ferro heme e não heme, sendo que a dose de $3 \mathrm{kGy}$ foi a que apresentou os maiores valores, independente do tipo de antibiótico utilizado. Para o ferro heme o antibiótico norfloxacina apresentou os maiores valores e para o ferro não heme os maiores valores foram notados para o antibiótico ciprofloxacina.

Palavras-chave: irradiação; carne; coelho; ferro.

\begin{abstract}
The growth in national production of rabbit meat demands greater knowledge of the characteristics of the meat, as well as the effects of a process that allows greater conservation of the meat. Frozen cuts of rabbit meat: thigh, ham and loin, treated with two types of antibiotics (norfloxacyn and ciprofloxacin), were irradiated in doses of 0,3 and $6 \mathrm{kGy}$, and the levels of heme and nonheme iron in the cuts were determined. The irradiation doses employed were influential on the levels of heme and nonheme iron, and the dose of $3 \mathrm{kGy}$ was the one that presented the largest values, independent of the type of antibiotic used. For heme iron, the antibiotic norfloxacyn presented the largest values and for nonheme iron the largest values were noted for the antibiotic ciprofloxacyn.
\end{abstract}

Keywords: irradiation, meat, rabbit, iron.

\section{Introdução}

A produção nacional de carne de coelho é baixa, quando comparada a outras carnes, e atende somente ao mercado interno. As regiões com predominância de descendente de europeus são as regiões de maior consumo desse tipo de carne. Possivelmente por causa disso, a qualidade da carne de coelho brasileira é pouco estudada se comparada com a carne de outros animais comerciais. Dessa forma, os critérios para a definição de uma carne de qualidade estão baseados nos atributos dados a outros tipos de carnes (FURUKAWA, 2002).

Estudos indicam que a carne de coelho possui altas quantidades de proteínas, e baixos níveis de sódio, gordura e colesterol, constituindo alimento benéfico para a dieta humana, se comparada com outros tipos de carnes (FERNÁNDEZ-ESPLÁ; O'NEILL, 1993; BADR, 2004). A carne é importante fonte de ferro, em especial porque fornece ferro heme que é absorvido independentemente de interações de outros componentes alimentares, o que não ocorre com o ferro não heme que sofre a influência de outras substâncias da dieta.

Os medicamentos veterinários vêm sendo usados nas criações comerciais para prevenir patologias ou mesmo para otimizar o crescimento dos animais além de atuarem como agentes terapêuticos (AERTS; HOGENBOOM; BRINKMAN, 1995).
Um número elevado de quinolonas e fluoroquinolonas foi aprovado e disponibilizado comercialmente para uso em animais de produção (SILVA, 2004). Entre os medicamentos empregados, temos as fluoroquinolonas que apresentam um átomo de flúor na posição 6 (SAMANIDOU; CRISTODOULOU; PAPADOYANNIS, 2005), sendo a ciprofloxacina e a norfloxacina pertencentes ao segundo grupo, que possui grande atividade antimicrobiana contra a maioria das bactérias Gram-negativas e algumas Gram-positivas (AFSSA, 2000; MARTINEZ; MCDERMOTT; WALKER, 2006).

Devido às grandes distâncias entre as regiões de produção e consumo, a comercialização da carne de coelho pelas grandes redes de supermercado é feita através do oferecimento da carcaça congelada, com o objetivo de estender sua preservação (ZOTTE, 2002).

Uma alternativa para a preservação da carne de coelho é a irradiação. A irradiação é um método eficiente para aumentar a segurança (patógenos, parasitas), preservar alimentos, melhorar a qualidade (comparada a processos térmicos), manter e preservar os nutrientes contidos nos alimentos (NAM; AHN, 2002). Todos os nutrientes contidos na carne são importantes para a saúde humana, destacando-se os minerais ferro e zinco. Nas carnes, o

Recebido para publicação em 15/9/2007

Aceito para publicação em 15/4/2008 (002833)

${ }^{1}$ Laboratório de radioentomologia e irradiação de alimentos, Centro de Energia Nuclear na Agricultura, Universidade de São Paulo - USP, CEP 13416-000 Piracicaba - SP, Brasil

${ }^{2}$ Departamento Agroindústria, Alimentos e Nutrição, Escola Superior de Agricultura Luiz de Queiroz - ESALQ, Piracicaba - SP, Brasil, E-mail: sgcbraza@esalq.usp.br

${ }^{*}$ A quem a correspondência deve ser enviada 
ferro é encontrado na forma heme, de mais fácil absorção pelo organismo do que o ferro não heme (VALLE, 2000). As alterações provocadas pela irradiação podem aumentar ou diminuir a quantidade de ferro presente nas carnes. Com o objetivo de compreender o efeito de diferentes doses de irradiação, esta pesquisa avaliou a disponibilidade de ferro heme e não heme, colesterol, TBA e capacidade de retenção de água em diferentes cortes da carne de coelho que receberam dois diferentes antibióticos. A importância de dados sobre a influência de antibióticos em carnes é necessária visto que no mercado interno ainda há a liberação do uso de antibióticos em carnes e somente em carnes tipo exportação esse tipo de prática é proibida.

\section{Material e métodos}

\subsection{Matéria-prima}

A carne dos coelhos foi obtida de experimento conduzido no Centro de Energia Nuclear na Agricultura (CENA) para estudo do efeito de antibióticos na carne, na qual foram empregados os antibióticos norfloxacina e ciprofloxacina, que foram administrados em 5 doses ( $\left.40 \mu \mathrm{g} \cdot \mathrm{Kg}^{-1}\right)$, uma a cada 2 semanas, totalizando 10 semanas de tratamento. No início do experimento os animais tinham 2 meses de idade. Os cortes utilizados no estudo foram coxa, pernil e lombo de coelhos, sendo utilizadas 3 amostras de cada corte. Estes foram embalados a vácuo, congelados e irradiados nas doses de 0, 3 e $6 \mathrm{kG}$, no irradiador Multipróposito no Instituto de Pesquisas Energéticas Nucleares (IPEN), com taxa de dose de $6 \mathrm{kGy} \cdot \mathrm{h}^{-1}$. As análises químicas foram realizadas no Laboratório de Nutrição Humana da Escola Superior de Agricultura "Luiz de Queiroz", ESALQ/USP. As amostras foram armazenadas congeladas à temperatura de $-4{ }^{\circ} \mathrm{C}$ durante 6 meses. Foram utilizadas 3 amostras de cada corte para cada tratamento de irradiação e foram realizadas as análises em triplicata.

Todos os reagentes utilizados foram de grau analítico.

\subsection{Análises Químicas}

\section{Ferro heme e ferro não heme}

A determinação do ferro heme foi realizada utilizando-se o método descrito por Hornsey (1956), com algumas modificações. O método baseia-se na extração por acetona acidificada. As amostras da carne de coelho (5 g) foram colocadas em tubos de centrífuga de $50 \mathrm{~mL}$, e foram adicionados $20 \mathrm{~mL}$ de acetona e de $0,5 \mathrm{~mL}$ de $\mathrm{HCl}$. A seguir, adicionou-se água deionizada até que o volume total de água na amostra fosse equivalente a $4,5 \mathrm{~g}$. Para a determinação da quantidade de água a ser adicionada, foi determinada a umidade do material segundo AOAC (1992). As amostras foram então centrifugadas (Centrífuga modelo TDL80-2B, marca Centribio) a 2000 g por 15 minutos e filtradas em papel de filtro qualitativo (Marca Schleicher \& Chuell $n^{\circ} 1$ ). A absorbância do filtrado foi medida a $640 \mathrm{~nm}$ e, em seguida, foi calculado o conteúdo de ferro heme através da Equação 1:

\footnotetext{
Hematina $=A b s_{640 \mathrm{~nm}} * 680 * P_{\text {amostra }}$

Ferroheme $=\frac{\text { hematina } * 88,2}{P_{\text {amostra }} * 10000}$
}

Para a determinação do ferro não heme, amostras de carne de frango $(2 \mathrm{~g})$ foram pesadas e adicionaram-se $15 \mathrm{~mL}$ de solução extratora composta pela mistura de 1:1 de ácido tricloroacético $40 \%$ e $\mathrm{HCl} 6 \mathrm{~N}$, segundo Torrence e Bothwell (1968). Foi adicionado nitrito de sódio a 1\%, e então as amostras foram colocadas em banho de água quente $\left(50^{\circ} \mathrm{C}\right)$ por 18 horas, resfriadas e centrifugadas (Centrífuga modelo TDL80-2B, marca Centribio) a $2000 \mathrm{~g}$ por 10 minutos, sendo o sobrenadante filtrado e utilizado para a determinação do ferro não heme pelo método Ferrozine.

No método Ferrozine, segundo Stookey (1970) e Carter (1971), os filtrados obtidos acima receberam agente redutor a $1 \%$ (ácido ascórbico) e precipitante de proteínas (ácido tricloroacético $11 \%$ ) e, a seguir, foram centrifugados a $1000 \mathrm{~g}$ por 10 minutos. Ao sobrenadante foi adicionado $1 \mathrm{~mL}$ de acetato de amônio 20\%, seguido de $1 \mathrm{~mL}$ de reagente Ferrozine $1 \mathrm{mM}$. $\mathrm{O}$ reagente Ferrozine foi preparado da seguinte maneira: 5,14 g do reagente Ferrozine (marca Sigma) mais $100 \mathrm{~g}$ de cloridrato de hidroxilamina (marca Sigma) e $500 \mathrm{~mL}$ de ácido clorídrico, sendo o volume completado para $1 \mathrm{~L}$ com água deionizada. Essa mistura resultou no desenvolvimento de complexo colorido magenta, que foi determinado por absorbância a $562 \mathrm{~nm}$ em espectrofotômetro marca Beckman modelo DU640, em cubeta de vidro de 4,5 × 1,0 $\times 1,0 \mathrm{~cm}$. A quantidade de ferro não heme nos cortes foi determinada através da Equação 2:

Fenãoheme $=\frac{\left(A_{u}-A_{b}\right)}{\left(A_{g}-A_{b}\right)} * 100$

em que:

$\mathrm{A}_{\mathrm{u}}=$ absorbância lida;

$\mathrm{A}_{\mathrm{b}}=$ absorbância do branco; e

$\mathrm{A}_{\mathrm{g}}=$ absorbância do padrão.

No método Ferrozine, é necessária a preparação de um branco (no qual não se utiliza a amostra) e de uma solução padrão (preparada com sulfato de ferro e amônia).

\section{Capacidade de retenção de água}

A capacidade de retenção de água (CRA) foi medida pela metodologia de centrifugação, descrita por Hoffmann, Hamm e Bluchel (1982). Foi pesado $1 \mathrm{~g}$ de amostra no papel de filtro e inserido no tubo da centrífuga. Foi centrifugado por 4 minutos a $1500 \mathrm{Xg}$ e pesado. A água restante após a centrifugação foi quantificada pela secagem da amostra a $70^{\circ} \mathrm{C}$ por uma noite e a CRA, calculada de acordo com Equação 3:

$C R A=\frac{\left(P_{\text {aposscentrifuauạão }}-P_{\text {pós sec agem }}\right)}{P_{\text {inicial }}} * 100$

\section{Análise TBA}

As análises de TBA foram realizadas segundo metodologia descrita por Kanattt, Chander e Sharma (2005): foram pesados $4 \mathrm{~g}$ de amostra e misturados a $16 \mathrm{~mL}$ de ácido tricloroacético

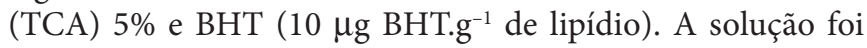


filtrada em papel de filtro. Foi acrescentado ao filtrado 0,02 M de TBA e foi aquecido em banho-maria a $45^{\circ} \mathrm{C}$ por 30 minutos. Depois de frio, a leitura foi feita a $532 \mathrm{~nm}$. Os valores de TBARS foram expressos em $\mathrm{mg}$ de malonaldeído por $\mathrm{kg}$ de carne.

\section{Colesterol}

Foi utilizada a metodologia de Bligh e Dyer (1959) para a extração de lipídios totais. A $2 \mathrm{~g}$ de amostra foram adicionados $10 \mathrm{~mL}$ de clorofórmio, $20 \mathrm{~mL}$ de metanol e $8 \mathrm{~mL}$ de água destilada e a solução foi agitada por 30 minutos. Foram adicionados novamente clorofórmio e sulfato de sódio (1,5\%) e agitados. As camadas foram separadas, sendo desprezada a camada superior e filtrada a camada inferior. Para a leitura do teor de colesterol, foi usado o método colorimétrico segundo Bohac et al. (1988), com a adição de $10 \mathrm{~mL}$ de $\mathrm{KOH}(12 \%)$ a $3 \mathrm{~mL}$ da amostra, a qual foi levada para banho-maria a $80{ }^{\circ} \mathrm{C}$ por 15 minutos. Foram acrescentados $5 \mathrm{~mL}$ de água destilada resfriados em torneira, cloreto de ferro e deixados em repouso por 15 minutos. Realizou-se a leitura da absorbância em $490 \mathrm{~nm}$ e os resultados foram expressos em mg. $100 \mathrm{~g}^{-1}$.

\subsection{Análise estatística}

O delineamento estatístico utilizado foi inteiramente casualizado. Foi realizada a análise de variância pelo teste F, e a comparação das médias obtidas nos diferentes tratamentos foi analisada segundo teste de Tukey $(\mathrm{p}<0,01)$ (PIMENTEL-GOMES, 1982), com utilização do programa Statistical Analysis System (SAS INSTITUTE, 1998), através da ferramenta ANOVA.

\section{Resultados e discussão}

\subsection{Ferro heme}

Os resultados obtidos nos experimentos encontram-se nas Tabelas 1 e 2 e indicam que tanto as doses de irradiação estudadas quanto os antibióticos empregados no experimento

Tabela 1. Efeito de diferentes antibióticos nos teores de ferro heme (mg.100 $\mathrm{g}^{-1}$ ) da coxa, pernil e lombo de coelhos tratados com diferentes antibióticos.

\begin{tabular}{cccc}
\hline Corte & Doses (kGy) & Norfloxacina & Ciprofloxacina \\
\hline Coxa & 0 & $3,21 \pm 0,06^{\mathrm{Cla} 2}$ & $1,60 \pm 0,02^{\mathrm{Cb}}$ \\
& 3 & $5,19 \pm 0,13^{\mathrm{Aa}}$ & $4,34 \pm 0,03^{\mathrm{Ab}}$ \\
\multirow{3}{*}{ Pernil } & 6 & $3,58 \pm 0,06^{\mathrm{Ba}}$ & $2,99 \pm 0,05^{\mathrm{Bb}}$ \\
& 0 & $2,12 \pm 0,08^{\mathrm{Ca}}$ & $2,14 \pm 0,04^{\mathrm{Ca}}$ \\
& 3 & $3,31 \pm 0,09^{\mathrm{Aa}}$ & $2,88 \pm 0,01^{\mathrm{Ab}}$ \\
Lombo & 6 & $2,53 \pm 0,03^{\mathrm{Ba}}$ & $2,38 \pm 0,02^{\mathrm{Bb}}$ \\
& 0 & $4,78 \pm 0,06^{\mathrm{Ca}}$ & $4,52 \pm 0,05^{\mathrm{Cb}}$ \\
& 3 & $7,64 \pm 0,35^{\mathrm{Aa}}$ & $6,63 \pm 0,04^{\mathrm{Ab}}$ \\
& 6 & $6,04 \pm 0,04^{\mathrm{Ba}}$ & $4,95 \pm 0,04^{\mathrm{Bb}}$ \\
\hline
\end{tabular}

${ }^{1}$ Letras maiúsculas na vertical indicam diferenças estatísticas entre doses para cada um dos cortes $(\mathrm{p}<0,01)$; $\mathrm{e}^{2}$ Letra minúscula na horizontal, diferença estatística entre antibióticos $(\mathrm{p}<0,01)$. se mostraram influentes nos teores de ferro heme dos cortes de coelho (Tabela 1).

Os maiores valores de ferro heme foram obtidos para a dose de $3 \mathrm{kGy}$ independente do tipo de antibiótico utilizado. $\mathrm{O}$ aumento nos valores de ferro heme na dose de $3 \mathrm{kGy}$ (Tabela 1), para o corte de pernil e lombo, podem ser explicados pela perda de água (Tabela 2).

Quanto maior a perda de água no corte, menos concentrados ficam os teores de ferro, visto que pode haver perda do ferro junto com a água. Como a mioglobina e outras proteínas heme são proteínas sarcoplasmáticas e estão localizadas dentro das células, são solúveis em água. Sendo assim, estas proteínas podem, em parte, ser perdidas com a ocorrência de exsudação, ou seja, durante a perda de umidade ou suco da carne (SHIMOKOMAKI et al., 2006). Esse aumento na perda de água foi observado antes da análise de ferro heme, em que foi feita a análise de umidade dos cortes. Os antibióticos estudados também se mostraram influentes, a norfloxacina apresentou valores superiores ao ciprofloxacina, mostrando que antibióticos influenciam de forma diferente na qualidade da carne pois são diferentes. A ciprofloxacina possui um grupo ciclopropil na posição N-1, o que melhora sua atividade antimicrobiana e também altera o seu comportamento em relação à norfloxacina (MARTINEZ; MCDERMOTT; WALKER, 2006; ROYBAL et al. 2002).

Os teores de ferro heme (Tabela 1) foram afetados pelo tipo diferente de antibiótico utilizado; outros fatores afetam também esses teores. Segundo pesquisas realizadas por Estévez e Cava (2004), Schricker e Miller (1983), os teores de ferro heme tendem a decrescer com o armazenamento e o cozimento, e o efeito da irradiação nas características nutricionais das carnes não são diferentes dos observados para outros métodos de conservação.

\subsection{Ferro não heme}

Os valores de ferro não heme encontrados demonstraram que a irradiação na dose de $3 \mathrm{kGy}$ foi a mais influente, apresentando os maiores valores (Tabela 3). O antibiótico que mais afetou os teores de ferro não heme foi a ciplofloxacina, que apresentou os maiores valores, quando comparados com os de norfloxacina, independente dos cortes estudados.

Tabela 2. Valores de umidade dos cortes de coelho estudados.

\begin{tabular}{cccc}
\hline Corte & Doses (kGy) & Norfloxacina & Ciprofloxacina \\
\hline Coxa & 0 & $64,22 \pm 0,06^{\mathrm{A} 1}$ & $84,23 \pm 0,16^{\mathrm{A}}$ \\
& 3 & $52,00 \pm 0,04^{\mathrm{C}}$ & $79,12 \pm 0,13^{\mathrm{C}}$ \\
& 6 & $59,56 \pm 0,09^{\mathrm{B}}$ & $82,59 \pm 0,20^{\mathrm{B}}$ \\
Pernil & 0 & $72,00 \pm 0,16^{\mathrm{A}}$ & $72,89 \pm 0,35^{\mathrm{A}}$ \\
& 3 & $70,00 \pm 0,10^{\mathrm{C}}$ & $71,54 \pm 0,18^{\mathrm{B}}$ \\
& 6 & $71,11 \pm 0,07^{\mathrm{B}}$ & $72,61 \pm 0,40^{\mathrm{A}}$ \\
\multirow{2}{*}{ Lombo } & 0 & $63,78 \pm 0,14^{\mathrm{A}}$ & $65,42 \pm 0,19^{\mathrm{B}}$ \\
& 3 & $58,67 \pm 0,12^{\mathrm{C}}$ & $59,47 \pm 0,17^{\mathrm{C}}$ \\
& 6 & $60,67 \pm 0,16^{\mathrm{B}}$ & $66,38 \pm 0,22^{\mathrm{A}}$ \\
\hline
\end{tabular}

${ }^{1}$ Letras diferentes na vertical indicam diferenças estatísticas entre doses para cada um dos cortes $(\mathrm{p}<0,01)$. 
Segundo Estévez e Cava (2004), o aumento da quantidade de ferro não heme em carnes é considerado um reflexo da diminuição de ferro heme como consequência da quebra da molécula heme durante o cozimento ou estocagem. Como a radiação ionizante pode afetar quimicamente proteínas e alterar a valência de íons metálicos, pode influenciar a disponibilidade de ferro em alimentos. Esse fato pode ser observado quando comparados os diferentes antibióticos empregados no estudo, pois os maiores valores de ferro não heme foram encontrados para o antibiótico ciprofloxacina que apresentou os menores valores de ferro heme.

\subsection{CRA}

A capacidade de retenção de água está ligada à maciez da carne. Quanto maiores os valores de CRA, mas macio o corte será. Os valores de CRA para carne de coelho irradiada se encontram na Tabela 4, na qual é observada uma maior maciez para os cortes que empregaram como antibiótico a ciprofloxacina e na dose de $3 \mathrm{kGy}$.

Dependendo da dose, várias mudanças organolépticas podem alterar a carne irradiada. A textura e a capacidade de retenção de água são alteradas pela desnaturação das proteínas estruturais (LAWRIE, 1985). A dose de $3 \mathrm{kGy}$ foi a que se

Tabela 3. Efeito de diferentes antibióticos nos teores de ferro não heme (mg.100 g ${ }^{-1}$ ) da coxa, pernil e lombo de coelhos tratados com diferentes antibióticos.

\begin{tabular}{cccc}
\hline Corte & Doses $(k G y)$ & Norfloxacina & Ciprofloxacina \\
\hline Coxa & 0 & $3,66 \pm 0,06^{\mathrm{Alb} 2}$ & $3,98 \pm 0,05^{\mathrm{Aa}}$ \\
& 3 & $2,64 \pm 0,01^{\mathrm{Cb}}$ & $2,99 \pm 0,03^{\mathrm{Ca}}$ \\
\multirow{3}{*}{ Pernil } & 6 & $2,91 \pm 0,01^{\mathrm{Bb}}$ & $3,19 \pm 0,03^{\mathrm{Ba}}$ \\
& 0 & $3,29 \pm 0,14^{\mathrm{Aa}}$ & $3,43 \pm 0,02^{\mathrm{Aa}}$ \\
& 3 & $2,35 \pm 0,06^{\mathrm{Cb}}$ & $2,72 \pm 0,04^{\mathrm{Ba}}$ \\
Lombo & 6 & $2,54 \pm 0,02^{\mathrm{Cb}}$ & $2,85 \pm 0,05^{\mathrm{Ba}}$ \\
& 0 & $3,53 \pm 0,04^{\mathrm{Aa}}$ & $3,56 \pm 0,01^{\mathrm{Aa}}$ \\
& 3 & $2,54 \pm 0,02^{\mathrm{Cb}}$ & $2,68 \pm 0,01^{\mathrm{Ca}}$ \\
& 6 & $2,90 \pm 0,01^{\mathrm{Bb}}$ & $3,13 \pm 0,02^{\mathrm{Ba}}$ \\
\hline
\end{tabular}

${ }^{1}$ Letras maiúsculas na vertical indicam diferenças estatísticas entre doses para cada um dos cortes $(\mathrm{p}<0,01)$; e ${ }^{2}$ Letra minúscula na horizontal, diferença estatística entre antibióticos para a mesma dose $(\mathrm{p}<0,01)$.

Tabela 4. Efeito de diferentes antibióticos nos teores de capacidade de retenção de água $\left(\mathrm{mg}^{-1} \mathrm{~g}^{-1}\right)$ da coxa, pernil e lombo de coelhos tratados com diferentes antibióticos.

\begin{tabular}{cccc}
\hline Corte & Doses $(k G y)$ & Norfloxacina & Ciprofloxacina \\
\hline Coxa & 0 & $23,00 \pm 0,01^{\mathrm{Clb} 2}$ & $44,33 \pm 0,05^{\mathrm{Ba}}$ \\
& 3 & $27,00 \pm 0,01^{\mathrm{Ab}}$ & $51,67 \pm 0,05^{\mathrm{Aa}}$ \\
\multirow{3}{*}{ Pernil } & 6 & $25,00 \pm 0,01^{\mathrm{Bb}}$ & $42,00 \pm 0,05^{\mathrm{Ca}}$ \\
& 0 & $23,00 \pm 0,01^{\mathrm{Bb}}$ & $48,33 \pm 0,05^{\mathrm{Ba}}$ \\
& 3 & $25,00 \pm 0,01^{\mathrm{Ab}}$ & $54,33 \pm 0,05^{\mathrm{Aa}}$ \\
Lombo & 6 & $25,00 \pm 0,01^{\mathrm{Ab}}$ & $49,67 \pm 0,05^{\mathrm{Ba}}$ \\
& 0 & $29,00 \pm 0,01^{\mathrm{Bb}}$ & $42,67 \pm 0,01^{\mathrm{Ba}}$ \\
& 3 & $31,00 \pm 0,01^{\mathrm{Ab}}$ & $48,00 \pm 0,02^{\mathrm{Aa}}$ \\
& 6 & $27,00 \pm 0,01^{\mathrm{Cb}}$ & $47,67 \pm 0,01^{\mathrm{Aa}}$ \\
\hline
\end{tabular}

${ }^{1}$ Letras maiúsculas na vertical indicam diferenças estatísticas entre doses para cada um dos cortes $(\mathrm{p}<0,01)$; $\mathrm{e}^{2}$ Letra minúscula na horizontal, diferença estatística entre antibióticos para a mesma dose $(\mathrm{p}<0,01)$. mostrou mais influente tanto para a capacidade de retenção de água quanto para os teores de ferro heme, apresentando os maiores valores. Isso demonstra que essa dose é melhor para a manutenção da qualidade da carne de coelho.

\subsection{TBA}

A oxidação lipídica é um fator muito importante na qualidade de carnes. Uma maior oxidação leva à formação de odores desagradáveis, principalmente em carnes irradiadas. Os níveis de TBA medidos para a carne de coelho irradiada e tratada com diferentes antibióticos se encontram na Tabela 5 .

Os maiores valores de oxidação foram observados para a dose de 0 kGy ou dose controle, indicando haver uma relação entre quantidade de ferro não heme e oxidação lipídica. Maiores valores de TBARS são notados quando se tem maiores valores de ferro não heme, visto que esse ferro é promotor de oxidações, sendo prejudicial à qualidade da carne.

\subsection{Colesterol}

Os níveis de colesterol são importantes para a decisão de compra de um consumidor. A Tabela 6 apresenta os valores de

Tabela 5. Efeito de diferentes antibióticos nos teores de TBA (mg malonaldeído. $\mathrm{kg}^{-1}$ ) da coxa, pernil e lombo de coelhos tratados com diferentes antibióticos.

\begin{tabular}{cccc}
\hline Corte & Doses (kGy) & Norfloxacina & Ciprofloxacina \\
\hline Coxa & 0 & $0,45 \pm 0,01^{\mathrm{Ala} 2}$ & $0,34 \pm 0,01^{\mathrm{Ab}}$ \\
& 3 & $0,31 \pm 0,01^{\mathrm{Ca}}$ & $0,22 \pm 0,01^{\mathrm{Cb}}$ \\
\multirow{3}{*}{ Pernil } & 6 & $0,39 \pm 0,01^{\mathrm{Ba}}$ & $0,27 \pm 0,01^{\mathrm{Bb}}$ \\
& 0 & $0,79 \pm 0,01^{\mathrm{Aa}}$ & $0,48 \pm 0,01^{\mathrm{Ab}}$ \\
& 3 & $0,52 \pm 0,01^{\mathrm{Ca}}$ & $0,34 \pm 0,01^{\mathrm{Cb}}$ \\
Lombo & 6 & $0,64 \pm 0,01^{\mathrm{Aa}}$ & $0,37 \pm 0,01^{\mathrm{Bb}}$ \\
& 0 & $0,62 \pm 0,01^{\mathrm{Aa}}$ & $0,39 \pm 0,01^{\mathrm{Ab}}$ \\
& 3 & $0,40 \pm 0,01^{\mathrm{Ca}}$ & $034 \pm 0,01^{\mathrm{Cb}}$ \\
& 6 & $0,51 \pm 0,01^{\mathrm{Ba}}$ & $0,37 \pm 0,01^{\mathrm{Bb}}$ \\
\hline
\end{tabular}

${ }^{1}$ Letras maiúsculas na vertical indicam diferenças estatísticas entre doses para cada um dos cortes $(\mathrm{p}<0,01)$; $\mathrm{e}^{2}$ Letra minúscula na horizontal, diferença estatística entre antibióticos para a mesma dose $(\mathrm{p}<0,01)$.

Tabela 6. Efeito de diferentes antibióticos nos teores de colesterol (mg.100 $\mathrm{g}^{-1}$ ) da coxa, pernil e lombo de coelhos tratados com diferentes antibióticos.

\begin{tabular}{cccc}
\hline Corte & Doses (kGy) & Norfloxacina & Ciprofloxacina \\
\hline Coxa & 0 & $86,35 \pm 0,58^{\mathrm{Ala} 2}$ & $78,09 \pm 0,07^{\mathrm{Ab}}$ \\
& 3 & $82,15 \pm 0,57^{\mathrm{Ba}}$ & $75,25 \pm 0,65^{\mathrm{Bb}}$ \\
\multirow{3}{*}{ Pernil } & 6 & $78,55 \pm 0,33^{\mathrm{Ca}}$ & $71,18 \pm 0,07^{\mathrm{Cb}}$ \\
& 0 & $85,54 \pm 0,18^{\mathrm{Aa}}$ & $75,71 \pm 0,18^{\mathrm{Ab}}$ \\
& 3 & $79,34 \pm 0,15^{\mathrm{Ba}}$ & $65,97 \pm 0,14^{\mathrm{Bb}}$ \\
Lombo & 6 & $75,57 \pm 0,29^{\mathrm{Ca}}$ & $53,61 \pm 0,11^{\mathrm{Cb}}$ \\
& 0 & $65,16 \pm 0,52^{\mathrm{Aa}}$ & $49,88 \pm 0,18^{\mathrm{Ab}}$ \\
& 3 & $61,38 \pm 0,18^{\mathrm{Ba}}$ & $43,72 \pm 0,25^{\mathrm{Bb}}$ \\
& 6 & $56,18 \pm 0,22^{\mathrm{Ca}}$ & $41,38 \pm 0,33^{\mathrm{Cb}}$ \\
\hline
\end{tabular}

${ }^{1}$ Letras maiúsculas na vertical indicam diferenças estatísticas entre doses para cada um dos cortes $(\mathrm{p}<0,01)$; $\mathrm{e}^{2}$ Letra minúscula na horizontal, diferença estatística entre antibióticos para a mesma dose $(\mathrm{p}<0,01)$. 
colesterol para os cortes da carne de coelho irradiadas e tratadas com antibióticos.

De acordo com os resultados encontrados, quanto maior a dose de irradiação aplicada aos cortes, menores os valores de colesterol encontrados. Isso está de acordo com Souza, Arthur e Canniatti-Brazaca (2007) que, trabalhando com carne de cordeiro, encontrou o mesmo comportamento e sugere que o colesterol é oxidado a outros tipos de gorduras.

\section{Conclusões}

A irradiação é um bom método para conservação da carne de coelhos, visto que ocorreu leve aumento nos teores de ferro heme, uma queda nos teores de colesterol e oxidação lipídica e ferro não heme. Os diferentes antibióticos da carne mostraram ter influência sobre a disponibilidade de ferro, tanto heme quanto não heme, e também sobre os demais aspectos analisados.

\section{Referências bibliográficas}

AERTS, M. M. L.; HOGENBOOM, A. C.; BRINKMAN, U. A. Analytical strategies for the creening of veterinary drugs and their residues in edible products. Journal of Chromatography B, v. 667, n. 1, p. 1-40, 1995.

AGENCE FRAÇAISE DE SECURITE SANITAIRE DES ALIMENTS AFSSA. High performance liquid chromatographic method with fluorescence detection for the quantification of quinolones in muscle. Paris, 2000. 26 p.

ASSOCIATION OF OFFICIAL THE ANALYTICAL CHEMISTS AOAC. Official methods of the AOAC. 12 ed. Washington, 1992. (v. 2)

BADR, H. M. Use of irradiation to control foodborne pathogens and extend the refrigerated market life of rabbit meat. Meat Science, v. 67, n. 4 , p. 541-548, 2004.

BLIGH, E. G.; DYER, W. J. A rapid method for total lipid extraction and purification. Journal of Physiology and Biochemistry, v. 37, n. 8, p. 911-917, 1959

BOHAC, C. E. et al. Assessment of methodologies for colorimetric colesterol assay of meats. Journal of Food Science, v. 53, n. 6, p. $1642-1644,1988$.

CARTER, P. Spectrophotometric determination of serum iron at the submicrogram level with a new reagent (Ferrozine). Analytical Biochemistry, v. 40, n. 2, p. 450-458, 1971.

ESTÉVEZ, M.; CAVA, R. Lipid and protein oxidation, release of iron from heme molecule and colour deterioration during refrigerated storage of liver pâté. Meat Science, v. 68, n. 4, p. 551-558, 2004.

FERNÁNDEZ-ESPLÁ, M. D.; O’NEILL, E. Lipid oxidation in rabbit meat under different storage conditions. Journal of Food Science, v. 58 , n. 6 , p. $1262-1264,1993$.

FURUKAWA, V. A. Efeito da suplementação de vitamina E na dieta sobre a qualidade da carne congelada de coelhos. Pirassununga, 2002.
64 p. Dissertação (Mestrado em Zootecnia) - Faculdade de Zootecnia e Engenharia de Alimentos - FZEA.

HOFFMANN, H.; HAMM, R.; BLUCHEL, E. Neus uber die bestimung der wasserbinding des nut hielf filter paper premethods. Fleishwirtchaft, v. 62, n. 1, p. 87-94, 1982.

HORNSEY, H. C. The color of cooked cured pork. Journal of the Science of Food and Agriculture, v. 7, n. 8, p. 534-540, 1956.

KANATT, S. R.; CHANDER, R.; SHARMA, A. Effect of radiation processing on the quality of chilled meat products. Meat Science, v. 69, n. 2, p. 269-275, 2005.

LAWRIE, R. A. Meat Science. New York: Pergamon Press, 1985. 267 p.

MARTINEZ, M.; MCDERMOTT, P.; WALKER, R. Pharmacology of the fluoroquinolones: A perspective for the use in domestic animals. The Veterinary Journal, London, v. 172, n. 1, p. 10-28, 2006.

NAM, K.C.; AHN, D.U. Carbon monoxide-heme pigment is responsible for the pink color in irradiated raw turkey breast meat. Meat Science, v. 60, n. 1, p. 25-23, 2002.

PIMENTEL-GOMES, F. Curso de estatística experimental. 10 ed. São Paulo: Nobel, 1982.

ROYBAL, J. E. et al. Determination of four fluoroquinolone in milk by liquid chromatography. Journal of Chromatography B, v. 780, n. 1, p. 83-92, 2002.

SAS Institute. SAS user's guide: statistic. Version 6. 12 ed. Cary, 1998, $846 \mathrm{p}$.

SAMANIDOU, V. F.; CRISTODOULOU, E. A.; PAPADOYANNIS, I. $\mathrm{N}$. Direct determination of five fluoroquinolones in chicken whole blood and in veterinary drugs by HPLC. Journal of Separation Science, v. 28, n. 4, p. 325-331, 2005.

SCHRICKER, B. R.; MILLER, D. D. Effects of cooking and chemical treatment on heme and nonheme iron in meat. Journal of Food Science, v. 48, n. 7, p. 1340-1344, 1983.

SHIMOKOMAKI, M. et al. Atualidades em Ciência e Tecnologia de Carnes. São Paulo: Editora Varela, 2006. 236 p.

SILVA, R. G. Farmacocinética e determinação de resíduos de enrofloxacina e seu metabólito em tecidos de frangos. Campinas, 2004. 127 p. Tese (Doutorado em Ciências) Universidade Estadual de Campinas - UNICAMP.

SOUZA, A. R. M.; ARTHUR, V.; CANNIATTI-BRAZACA, S. G. Alterações provocadas pela irradiação e armazenamento nos teores de ferro heme em carne de frango. Ciência e Tecnologia de Alimentos, v. 27, n. 1, p. 67-71, 2007.

STOOKEY, L. L. A new spectrophotometric reagent for iron. Analytical Chemistry, v. 42, n. 7, p. 779-781, 1970.

TORRENCE, J. D.; BOTHWELL, T. H. A simple technique for measuring storage iron concentrations in formalinised liver samples. South African Medical Journal, v. 33, n. 1, p. 9-11, 1968 .

VALLE, E. R. Mitos e realidades sobre o consumo de carne bovina. Campo Grande: Embrapa Gado de Corte, 2000. 33 p.

ZOTTE, A. D. Perception of rabbit meat quality and major factors influencing the rabbit carcass and meat quality. Livestock Production Science, v. 75, n. 1, p.11-31, 2002. 